\title{
Use of Intact Xenopus Oocytes in Nucleocytoplasmic Transport Studies
}

\author{
Nelly Panté
}

\begin{abstract}
Summary
Because of its large nucleus, the Xenopus laevis oocyte offers an excellent system to study nucleocytoplasmic transport. This system, in combination with electron microscopy, has provided much of our insight into the mechanisms of nuclear import and export. In a typical experiment, the nuclear transport substrate is first labeled with colloidal gold, and the resulting complex is injected into the cytoplasm (to study nuclear import) or the nucleus (to study nuclear export) of Xenopus oocytes. The oocytes are then fixed, dehydrated, infiltrated, and embedded into an epoxy resin. Following resin polymerization, thin sections of oocyte nuclei are obtained and examined under an electron microscope. Subsequent evaluation of the position and distribution of the gold-labeled substrate reveals whether the substrate has undergone nuclear import (or export) and the position of ratelimiting events. This chapter describes in detail the protocols for performing electron microscopy import assays with Xenopus oocytes and presents some data illustrating the types of experiments possible using this system.
\end{abstract}

Key Words: Electron microscopy; microinjection; nuclear import; nuclear pore complex; Xenopus oocyte.

\section{Introduction}

Microinjection of Xenopus laevis oocytes has provided an excellent in vivo system to study nucleocytoplasmic transport. They are a popular model because the large size of the oocytes and their nuclei $(\sim 0.4 \mathrm{~mm})$ make their manipulation and injection relatively easy. Moreover, detection of transport substrate after the transport assay involves well-established techniques. The use of intact Xenopus oocytes to study nucleocytoplasmic transport also has advantages over in vitro systems (e.g., Xenopus egg extract reconstitution system [1], digitonin-permeabilized cells [2]) in that all the essential protein factors necessary for transport are present in high amounts in the oocyte. Therefore, one only requires oocytes and the transport probe or substrate. 
To study nuclear transport in Xenopus oocytes, normally a transport substrate is microinjected into the cytoplasm of the oocyte (for a study of nuclear import) or the nucleus (for a study of nuclear export). After the transport reaction occurs (10-60 min after the injection depending on the site of injection), the transported substrate is detected in the individual compartments (cytoplasm and nucleus). Studies using radioactively labeled substrates require manual isolation of the nucleus and cytoplasm of the injected oocytes. The transported substrate is then detected by sodium dodecyl sulfate-polyacrylamide gel electrophoresis and autoradiography (3-6). However, detection of the transported molecules by electron microscopy (EM) offers more information about the transport process because the structure of the nuclear pore complex (NPC) of Xenopus oocyte nuclei is highly preserved. Thus, EM detection allows visualization of the transport of particular ligands through single NPCs at the level of distinct NPC components (see Fig. 1). This chapter describes the methods of studying nucleocytoplasmic transport of microinjected Xenopus oocytes using EM.

The EM transport assay in the Xenopus oocyte requires the transport substrate to be labeled with electron-opaque particles. Feldherr was the first to use embedding and thin-sectioning EM of amphibian oocytes microinjected with colloidal gold particles (7). His pioneer studies using colloidal gold coated with nucleoplasmin (a nuclear protein from $X$. laevis that contains two nuclear localization signals [NLSs]) were fundamental in demonstrating that proteins enter the nucleus through the NPC (8). Using the same approach, in vivo interactions between the nucleoplasmin-coated gold particles and structural components of the NPC have been depicted $(\mathbf{9}, \mathbf{1 0})$. For example, interactions of the nucleoplasmin-gold particles with filaments that protrude from the NPC were documented by EM visualization of nuclear import in Xenopus oocytes $(\mathbf{9}, \mathbf{1 0})$.

Experimental designs using inhibitors of nuclear transport have also been explored to map intermediates arrested at the NPC of Xenopus oocytes $(10,11$; see Fig. 2). For example, the lectin wheat germ agglutinin (WGA) is known to inhibit nuclear import $(\mathbf{1 2}, 13)$. When WGA is preinjected in Xenopus oocytes to inhibit nuclear import of gold particles coated with nucleoplasmin, the gold-nucleoplasmin particles are arrested at the terminal end of the cytoplasmic filaments of the NPC (10; see Fig. 2A). Similarly, we have arrested NLS-import substrates at the nuclear side of the NPC when oocytes are coinjected with a mutant form of the transport factor importin- $\beta$, which does not bind Ran (11; see Fig. 2C). This importin- $\beta$ mutant failed to deliver the NLS-import substrate into the nucleus, which indicates that the Ran binding site in importin- $\beta$ is essential for the last step of the nuclear import of cNLS-bearing proteins. Thus, these EM studies revealed the distinct molecular steps of the mechanism of protein import into the nucleus.

Nuclear transport assays using Xenopus oocytes have also been very valuable for the study of nuclear import of other substrates, including viral capsids $(\mathbf{1 4 , 1 5})$. In particular, nuclear import of the spliceosomal uridine-rich small nuclear ribonucleoprotein particles (U snRNPs) has been extensively studied in Xenopus oocytes $(\mathbf{5 , 1 6}$ 20). Most of these studies involved detection of radioactively labeled probes. However, EM in combination with colloidal gold has also been used to follow the nuclear import of U1 snRNPs (20). 

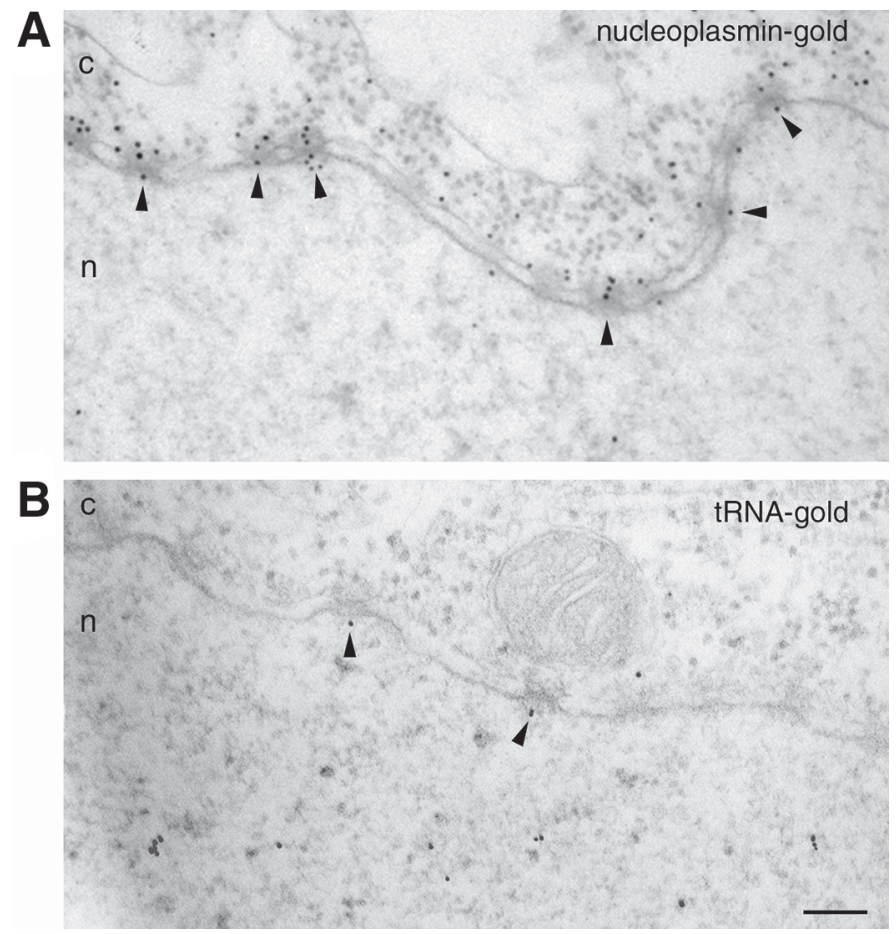

Fig. 1. EM visualization of nucleocytoplasmic transport of gold particles coated with transport substrate in Xenopus oocytes. (A) Nuclear import of nucleoplasmin-coated gold particles. The 8-nm diameter gold particles were coated with nucleoplasmin (as indicated in Subheading 3.1.2.) and injected into the cytoplasm of Xenopus oocytes. After incubation for $1 \mathrm{~h}$ at room temperature, the oocytes were processed for embedding and thin-sectioning EM, as indicated in Subheading 3.3. (B) Nuclear export of transfer RNA-coated gold particles. The 8-nm diamter gold particles were coated with transfer RNA (as indicated in Subheading 3.1.3.), and injected into the nucleus of Xenopus oocytes. After incubation for $30 \mathrm{~min}$ at room temperature, the oocytes were processed for embedding and thin-sectioning EM, as indicated in Subheading 3.3. Shown are views of nuclear envelope cross sections with adjacent cytoplasm (c) and nucleoplasm (n). Arrowheads point to NPCs that are actively transporting the transport substratecoated gold particles. Scale bar $200 \mathrm{~nm}$.

Xenopus oocytes are the system of choice for the study of nuclear export, and most of our insight into the mechanism of ribonucleic acid (RNA) nuclear export has come from these studies. A summary of these studies, as well as the methods for nuclear export of RNAs, was presented (21). Again, most of these studies were performed with ${ }^{32} \mathrm{P}$-labeled RNAs. However, although less popular, gold-conjugated RNAs have also been used $(22,23)$.

For EM analysis of the injected oocytes, conventional embedding and thin sectioning is normally used, and the samples are examined by transmission EM. This meth- 

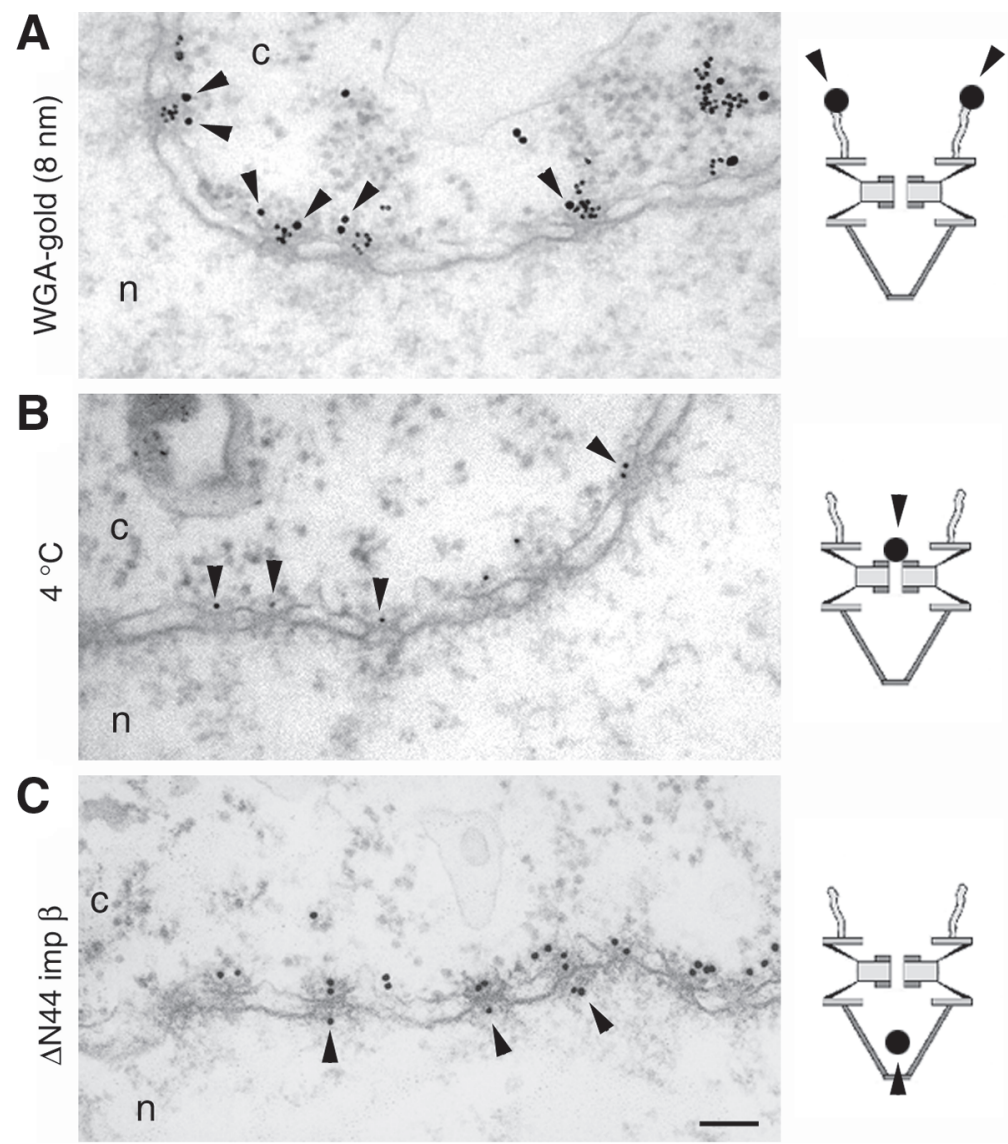

Fig. 2. EM visualization of transport-arrested intermediates at the NPC depicted with three different inhibitors of nuclear import. (A) WGA inhibits translocation of nucleoplasmin-coated gold particles through the NPC but not its initial binding to the NPC cytoplasmic filaments. For these experiments, 8-nm gold particles were coated with WGA and preinjected into the cytoplasm of Xenopus oocytes. After incubation for $1 \mathrm{~h}$ at room temperature, the oocytes were injected with 14-nm gold particles coated with nucleoplasmin, incubated for $1 \mathrm{~h}$ at room temperature, and processed for embedding and thin-sectioning EM. The 8-nm WGA-gold particles bind to the center of the NPC, and the 14-nm nucleoplasmin-gold particles are found at a distance corresponding to the distal end of the cytoplasmic NPC filaments (arrowheads). (B) Inhibition of nuclear import by chilling arrests nucleoplasmin-coated gold particles at the cytoplasmic entrance of the NPC central channel. Oocytes were cooled at $4^{\circ} \mathrm{C}$ for $1 \mathrm{~h}$ before injection with 8-nm gold particles coated with nucleoplasmin. During injection, oocytes were kept on an ice bath. After injection, the oocytes were incubated for $1 \mathrm{~h}$ at $4{ }^{\circ} \mathrm{C}$ and then processed for embedding and thin-sectioning EM. (C) Gold particles coated with import substrates are arrested at the nuclear side of the NPC, when nuclear import is followed in the presence of 
odology reveals side views of the NPCs (see Figs. 1,2). However, other EM specimen preparations and even visualizations by atomic force microscopy (24) or field emission scanning EM (25) are possible. The preparation of injected oocytes using unconventional EM techniques, including cryo-EM (26), metal shadowing (27), and quick freezing/freeze-drying/rotary metal shadowing (10), was used in the past to detect nuclear import of gold-labeled nucleoplasmin after microinjection into Xenopus oocytes. However, these state-of-the-art EM techniques are not accessible to most researchers because they require specialized instrumentation. Therefore, the current chapter focuses on the methods used to analyze the injected oocytes by conventional embedding and thin-sectioning EM. They require equipment commonly present in many EM facilities and laboratories, thereby increasing the usefulness of this research.

\section{Materials}

1. $\mathrm{HAuCl}_{4}$ (Sigma).

2. Sodium citrate.

3. Tannic acid.

4. $\mathrm{KCO}_{3}$.

5. $10 \% \mathrm{NaCl}$.

6. Specimen EM grids: 200-mesh/in, copper grids coated with a specimen support film (collodion/carbon or formvar/carbon).

7. Import substrate (e.g., nucleoplasmin, bovine serum albumin [BSA] coupled to the peptide CGGGPKKKRKVED [a classical NLS], U1 snRNP).

8. BSA (Sigma).

9. Beckman tabletop ultracentrifuge and rotor TLA 120.2.

10. $\mathrm{Th}\left(\mathrm{NO}_{3}\right)_{4}$.

11. Export substrate (e.g., messenger RNA, transfer RNA, U1 RNA, proteins containing nuclear export signal).

12. Uranyl acetate.

13. Xenopus laevis.

14. Tricaine methane sulfonate MS222 (Sigma).

15. Sodium bicarbonate.

16. Modified Barth's saline (MBS) buffer: $88 \mathrm{mM} \mathrm{NaCl}, 1 \mathrm{~m} M \mathrm{KCl}, 0.82 \mathrm{mM} \mathrm{MgSO}_{4}$, $0.33 \mathrm{mM} \mathrm{Ca}\left(\mathrm{NO}_{3}\right)_{2}, 0.41 \mathrm{~m} M \mathrm{CaCl}_{2}, 10 \mathrm{~m} M$ HEPES, $\mathrm{pH}$ 7.5.

17. Collagenase (Sigma).

(caption continued from previous page) a mutant form of importin- $\beta$ lacking the first 44 amino acid residues $(\Delta \mathrm{N} 44$-imp $\beta)$. For these experiments, the importin $\beta$-binding domain of importin- $\alpha$ (the IBB domain, which is a monovalent substrate) was used as the import substrate. Gold particles $14 \mathrm{~nm}$ in diameter were first coated with the IBB domain, and the IBBcoated gold particles were preincubated at $4^{\circ} \mathrm{C}$ for $1 \mathrm{~h}$ with $\Delta \mathrm{N} 44$-imp $\beta$ at a $1 / 1$ molar ratio. This mixture was then injected into the cytoplasm of Xenopus oocytes. After injection, the oocytes were incubated at room temperature for $2 \mathrm{~h}$ and then processed for embedding and thin-sectioning EM. The electron micrographs show cross sections of nuclear envelopes with NPC-arrested intermediates (arrowheads). The $\mathrm{c}$ and $\mathrm{n}$ indicate the cytoplasm and nucleus, respectively. On the right are schematic diagrams of the NPC indicating the distinct arrested intermediates (arrowheads) visualized by EM. Scale bar, $200 \mathrm{~nm}$. 
18. Calcium-free MBS: MBS without $\mathrm{Ca}\left(\mathrm{NO}_{3}\right)_{2}$ and $\mathrm{CaCl}_{2}$.

19. Penicillin/streptomycin (Sigma).

20. Oocyte microinjector.

21. Dissecting microscope.

22. Dissecting forceps.

23. Glutaraldehyde.

24. Low-salt buffer (LSB): $1 \mathrm{~m} M \mathrm{KCl}, 0.5 \mathrm{~m} M \mathrm{MgCl}_{2}, 10 \mathrm{~m} M$ HEPES, $\mathrm{pH}$ 7.5.

25. Low-melting agarose.

26. $\mathrm{OsO}_{4}$.

27. Ethanol.

28. Acetone.

29. Epon 812 (Fluka).

30. Ultramicrotome.

31. Lead citrate.

32. Electron microscope.

\section{Methods}

In general, the methods for the study of nucleocytoplasmic transport in Xenopus oocyte by EM include (1) gold conjugation of transport substrates, (2) microinjection of oocytes with gold-conjugated transport substrate, (3) preparation of injected oocytes for EM, and (4) EM visualization and image recording. The details of these procedures are outlined next.

\subsection{Gold Conjugation of Transport Substrates}

Colloidal gold particles have been utilized for both nuclear import (7-10) and nuclear export $(22,23)$. These particles are very electron dense and easy to visualize on the EM. They can also be used in different sizes to study nuclear transport of different substrates at the same time or to visualize biochemical inhibitors of nuclear transport (i.e., WGA, antibodies; see Fig. 2). Colloidal gold in a variety of sizes is commercially available or can be easily produced using a procedure described in Subheading 3.1.1. After the gold particles are obtained, they are coated with the transport substrate. Outlined next are the methods for coating colloidal gold particles with proteins (Subheading 3.1.2.) and RNAs (Subheading 3.1.3.).

\subsubsection{Preparation of Colloidal Gold}

Our standard procedure to make gold particles $8 \mathrm{~nm}$ in diameter is through reducing tetrachloroauric acid with sodium citrate and tannic acid (28). Described here are the steps to make $100 \mathrm{~mL}$ of 8-nm gold particles (see Note 1). For 15-nm gold particles, we used $0.1 \mathrm{~mL} 1 \%$ tannic acid and $0.1 \mathrm{~mL} 25 \mathrm{mM} \mathrm{KCO}$.

1. Make an $80-\mathrm{mL}$ solution (solution $\mathrm{A}$ ) of $0.01 \% \mathrm{HAuCl}_{4}$ by diluting $1 \%$ stock solution of $\mathrm{HAuCl}_{4}$ (Sigma).

2. Make the reduction solution (solution $\mathrm{B}$ ) by mixing the following: $4 \mathrm{~mL} 1 \%$ sodium citrate (freshly made), $0.5 \mathrm{~mL} 1 \%$ tannic acid (freshly made), $0.5 \mathrm{~mL} 25 \mathrm{mM} \mathrm{KCO}_{3}$ (freshly made), and $15 \mathrm{~mL}$ distilled water

3. Pour solution A into a 250 -mL Erlenmeyer flask and heat to $60^{\circ} \mathrm{C}$ while stirring. 
4. When solution A reaches $60^{\circ} \mathrm{C}$, immediately add solution $\mathrm{B}$ and boil for about $2 \mathrm{~min}$ while stirring. The solution will become red when it boils.

5. Cool the solution. Pour the colloidal gold solution into a sterile container (e.g., a tissue culture flask) and store in the dark at room temperature.

6. Check the quality and size of the gold particles by EM. For this purpose, a 5- $\mu \mathrm{L}$ drop of the colloidal gold solution is placed onto a specimen copper EM grid. After 2 to $5 \mathrm{~min}$, blot the excess liquid by gently touching the grid with filter paper. Let the grid dry. Examine the grid using EM.

\subsubsection{Conjugation of Proteins With Colloidal Gold}

Colloidal gold particles are negatively charged. Positively charged proteins are adsorbed by noncovalent binding (i.e., ionic and hydrophobic interactions) on the surface of gold particles. During the reaction, protein molecules are added to the surface of the gold particle until its negative charge is stabilized. However, if not enough molecules are available, the gold particles will not be electrically stable and will interact with molecules in the cell on microinjection. It is also very important not to have an excess of proteins because the free proteins inhibit the import of the gold-conjugated protein and cause competition.

Thus, the first step in the preparation of gold-protein conjugates is determining the minimal amount of protein required for the stabilization of gold particles. This is accomplished by mixing small amounts of colloidal gold with varied (decreasing) amounts of protein. The stability of gold particles is monitored by a red-to-blue color change on the addition of an electrolyte $(\mathrm{NaCl})$. This color shift is caused by aggregation (flocculation) of the unstable gold particles. This test is called a flocculation test. The following steps compose a flocculation test:

1. Centrifuge the protein suspension at full speed in an Eppendorf centrifuge for $10 \mathrm{~min}$ to eliminate aggregates.

2. Spread a sheet of parafilm on a white background (e.g., white tray) and place 5 - $\mu \mathrm{L}$ drops of serially diluted protein suspension (to dilute the protein, use phosphate-buffered saline or a buffer in which the protein is usually kept).

3. Add $25 \mu \mathrm{L}$ colloidal gold to each drop of protein suspension. Mix each drop well by repeated pipeting up and down with a $50-\mu \mathrm{L}$ pipetor.

4. Add $25 \mu \mathrm{L} 10 \% \mathrm{NaCl}$ to each drop and mix well again by pipeting up and down.

5. Visually check the color of the drops. The slightest change of color (from red to blue) indicates the instability of the gold complex.

6. The amount of protein required to stabilize $25 \mu \mathrm{L}$ of colloidal gold can be estimated as twice the concentration of the point at which the color change was observed. For example, if the color changed at a protein concentration of $0.05 \mathrm{mg} / \mathrm{mL}, 5 \mu \mathrm{L}$ of protein at $0.1 \mathrm{mg} / \mathrm{mL}$ is the right amount to stabilize $25 \mu \mathrm{L}$ of colloidal gold. Note, however, that it is not necessary to know the exact concentration of the protein. For example, if the color changed when the dilution of the protein was $1 / 20,5 \mu \mathrm{L}$ of a $1 / 10$ dilution would be the right amount of protein to stabilize $25 \mu \mathrm{L}$ of colloidal gold (see Note 2 ).

To finalize the preparation of the protein-coated gold particles, the amount of protein necessary to mix with 0.5 to $1 \mathrm{~mL}$ of gold $(0.5 \mathrm{~mL}$ is more than enough for a couple of experiments) needs to be scaled. Then, follow this procedure: 
1. Add the colloidal gold to an Eppendorf tube.

2. Add the protein to the tube in the ratio determined by the flocculation test.

3. Slowly stir for $5 \mathrm{~min}$.

4. Add BSA to a final concentration of $0.1 \%$ and stir for 10 min (see Note 3).

5. Centrifuge for $15 \mathrm{~min}$ at $32,000 \mathrm{rpm}$ at $4^{\circ} \mathrm{C}$ in a Beckman tabletop ultracentrifuge (rotor TLA 120.2). After centrifugation, the supernatant will be clear, and the pellet will consist of red sediment on the bottom of the centrifuge tube.

6. Carefully remove the supernatant and resuspend the loose sediment in a small volume (20-100 $\mu \mathrm{L}$ ) of a convenient buffer (phosphate-buffered saline or the normal buffer in which the protein is usually kept) containing $0.1 \%$ BSA. Store in the dark at $4^{\circ} \mathrm{C}$ (see Note 4).

7. Check the quality of the protein-coated gold particles by negative-staining EM. For this purpose, a 5- $\mu \mathrm{L}$ drop of the gold-protein solution is placed onto a specimen EM grid. After 2 to 5 min of adsorption, blot the excess liquid by gently touching the grid with a filter paper. Wash grids on 4 drops of distilled water by placing the grid on top of the drops. Remove excess water from the grid and add $5 \mu \mathrm{L} 1 \%$ uranyl acetate. After $1 \mathrm{~min}$, remove the drop of uranyl acetate and let the grid dry. Examine the grid using EM.

\subsubsection{Conjugation of RNA With Colloidal Gold}

To conjugate RNA with colloidal gold, first positively charged colloidal gold is prepared using $\mathrm{Th}\left(\mathrm{NO}_{3}\right)_{4}$. The amount of $\mathrm{Th}\left(\mathrm{NO}_{3}\right)_{4}$ required to reverse the charge of colloidal gold depends on the size of the gold particles and changes from batch to batch of colloidal gold. Thus, the following test needs to be done to determine the right amount of $\mathrm{Th}\left(\mathrm{NO}_{3}\right)_{4}$ necessary to reverse the charge of colloidal gold:

1. On a sheet of parafilm spread on a white background, place 5- $\mu \mathrm{L}$ drops of decreasing concentration of $\mathrm{Th}\left(\mathrm{NO}_{3}\right)_{4}$, starting with a $1 M$ concentration.

2. Add $50 \mu \mathrm{L}$ colloidal gold to each drop of $\mathrm{Th}\left(\mathrm{NO}_{3}\right)_{4}$. Mix each drop well by suctioning up and down with a $50-\mu \mathrm{L}$ pipetor.

3. Visually check the color of the drops. At higher concentrations of $\mathrm{Th}\left(\mathrm{NO}_{3}\right)_{4}$, the color of the drop changes from red to blue. At decreasing concentrations of $\mathrm{Th}\left(\mathrm{NO}_{3}\right)_{4}$, the color of the drop turns lilac and then red, corresponding to positively charged gold particles.

4. Estimate the amount of $\mathrm{Th}\left(\mathrm{NO}_{3}\right)_{4}$ necessary to reverse the charge of the gold particles by determining the concentration at which the drop changed color to lilac and then to red. Scale up this amount to make 5 to $20 \mathrm{~mL}$ of positively charged colloidal gold.

The method of conjugating RNA to positively charged colloidal gold particles is similar to that of conjugating protein described in Subheading 3.1.2. First, a flocculation test is performed to determine the amount of RNA required to stabilize the gold particles. This amount is scaled up to make large amounts of RNA-gold conjugates. After conjugation, the quality of the gold-RNA particles is checked by negatively staining as described in Subheading 3.1.2.

\subsection{Oocyte Preparation and Microinjection}

\subsubsection{Oocytes}

1. Surgically remove oocytes from narcotized female $X$. laevis. (To narcotize a frog, place the frog in a solution of $300 \mathrm{mg} / \mathrm{L}$ of Tricaine methane sulfonate MS222 [Sigma] that has been buffered to a $\mathrm{pH}$ of 7.5 with about $600 \mathrm{mg} / \mathrm{L}$ sodium bicarbonate for $45 \mathrm{~min}$.) 
2. Wash oocytes two or three times with MBS to remove traces of blood and debris.

3. Defolliculate oocytes by treating them with $5 \mathrm{mg} / \mathrm{mL}$ collagenase (Sigma) in calciumfree MBS for $1 \mathrm{~h}$. For this purpose, place oocytes into a 50-mL Falcon centrifuge tube together with $20 \mathrm{~mL}$ of $5 \mathrm{mg} / \mathrm{mL}$ collagenase in calcium-free MBS. Gently rock the tube for $1 \mathrm{~h}$ at room temperature (see Note 5).

4. Wash the oocytes three times with MBS.

5. Resuspend oocytes in MBS containing 1\% penicillin/streptomycin with MBS.

6. Transfer oocytes to a sterile Petri dish and keep at $4^{\circ} \mathrm{C}$.

7. Microinject the oocytes within the next $5 \mathrm{~d}$.

\subsubsection{Microinjection}

1. Using a dissecting microscope select oocytes at developmental stage VI. These oocytes are large, with good contrast between the black animal hemisphere and the creamy color vegetal hemisphere (see Fig. 3). If the oocytes were at $4^{\circ} \mathrm{C}$, let them warm to room temperature before microinjection.

2. Transfer mature stage VI oocytes into a microwell plate (Nalge Nunc, 10- $\mu \mathrm{L}$ well volume) filled with MBS (see Fig. 3). This should be done carefully, using a $50-\mu \mathrm{L}$ pipetor with a pipet tip that has been cut at the end to allow undisrupted suction of the oocytes.

3. Place one oocyte into each well and properly orient it for cytoplasmic or nuclear injection (see Fig. 3).

4. For cytoplasmic injection, inject $50 \mathrm{~nL}$ gold-conjugated import substrate into each oocyte. For consistency between each injection, inject each oocyte in its vegetal hemisphere, very close to the animal hemisphere.

5. For nuclear injection, position the oocyte in each well with the black animal pole (which contains the nucleus) facing upward (see Fig. 3). Cover the microwell plate with a lid, place it on a low-speed centrifuge, and centrifuge at $500 \mathrm{~g}$ for $15 \mathrm{~min}$. After centrifugation, the nucleus will be visible through the animal pole, thus increasing the accuracy of nuclear injection. If the nucleus is not visible, recentrifuge for $10 \mathrm{~min}$ (see Note 6). Inject $10 \mathrm{~nL}$ gold-conjugated export substrate into the nucleus of each oocyte.

6. Transfer injected oocytes into a small (35-mm diameter) Petri dish filled with MBS and incubate at room temperature for $1 \mathrm{~h}$ (see Note 7).

\subsection{Preparation of Injected Oocytes for Embedding and Thin-Sectioning EM}

1. After incubation of injected oocytes as indicated above, fix the oocytes overnight at $4{ }^{\circ} \mathrm{C}$ with $2 \%$ glutaraldehyde in MBS.

2. The next day, rinse the oocytes with MBS three times for 5 min each.

3. Place the oocytes into a small Petri dish (35-mm diameter) filled with LSB. Using dissecting forceps and a dissecting microscope, manually dissect the animal pole of the oocytes (see Note 8 and Fig. 4). At this point, the success of the microinjection can be evaluated by the presence of red color in the cytosol (for cytosolic injections) or a red nucleus (for nuclear injection). Follow the protocol only for the oocytes that were injected successfully.

4. Fix the dissected oocytes again with $2 \%$ glutaraldehyde in LSB for $1 \mathrm{~h}$ at room temperature.

5. Rinse the dissected oocytes three times in LSB for 5 min each and embed them in $2 \%$ low-melting agarose. Using a razor blade, cut small pieces of agar containing the dissected oocyte (see Fig. 4).

6. Postfix the agar-embedded oocytes with $1 \% \mathrm{OsO}_{4}$ in LSB for $1 \mathrm{~h}$. 


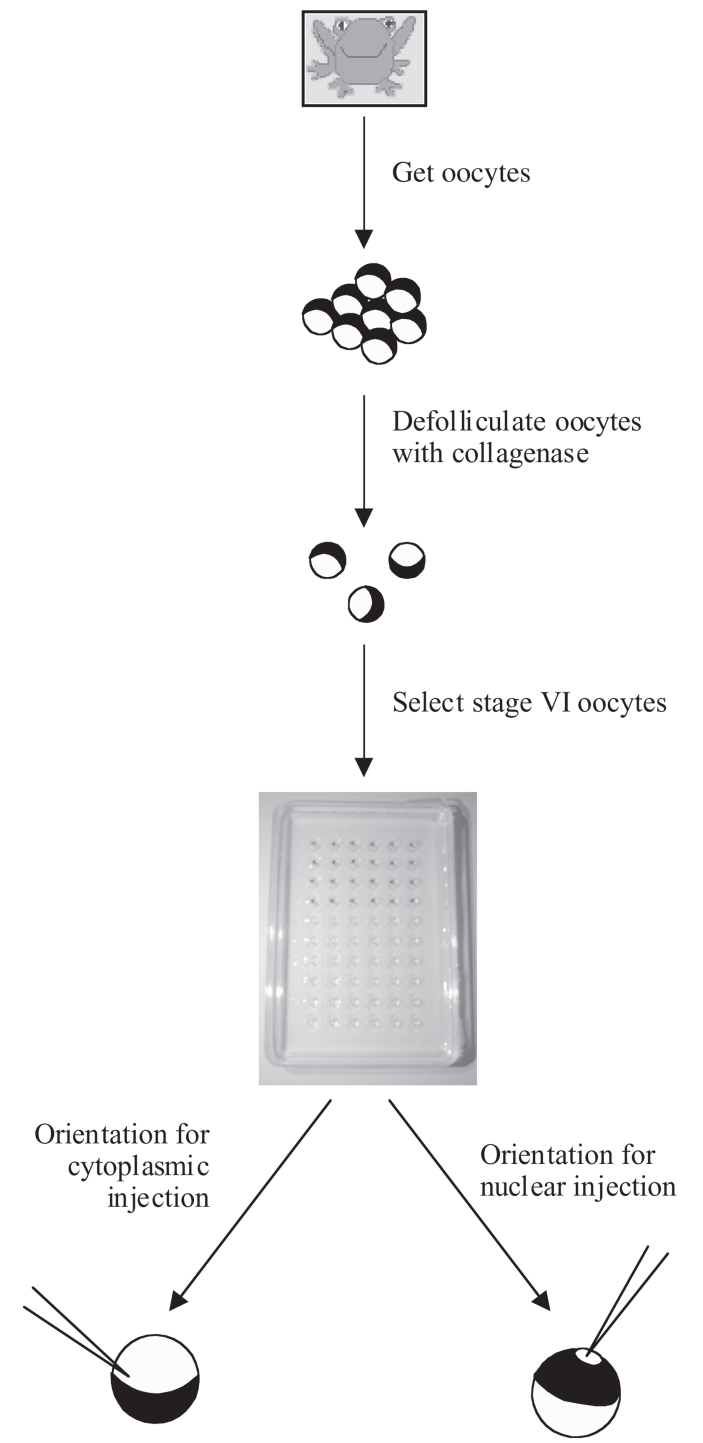

Fig. 3. Steps for preparing Xenopus oocytes for microinjection. For detail, see Subheading 3.2.

7. Rinse three times in LSB for 5 min each. If necessary, oocytes can be stored overnight at $4^{\circ} \mathrm{C}$, and the protocol can be continued the next day.

8. Sequentially dehydrate the agar-embedded oocytes in an ascending series of ethanol and embed in Epon (Fluka) as follows: dehydrate samples in 50, 70, and 90\% ethanol for $20 \mathrm{~min}$ each. Follow this with two changes in $100 \%$ ethanol for $20 \mathrm{~min}$ each. Finally, dehydrate with $100 \%$ acetone for $20 \mathrm{~min}$. Infiltrate with mixtures of Epon and acetone at a 1:1 ratio for $1 \mathrm{~h}$ and at a 2:1 ratio for $2 \mathrm{~h}$ and finally in pure Epon for at least $6 \mathrm{~h}$. 


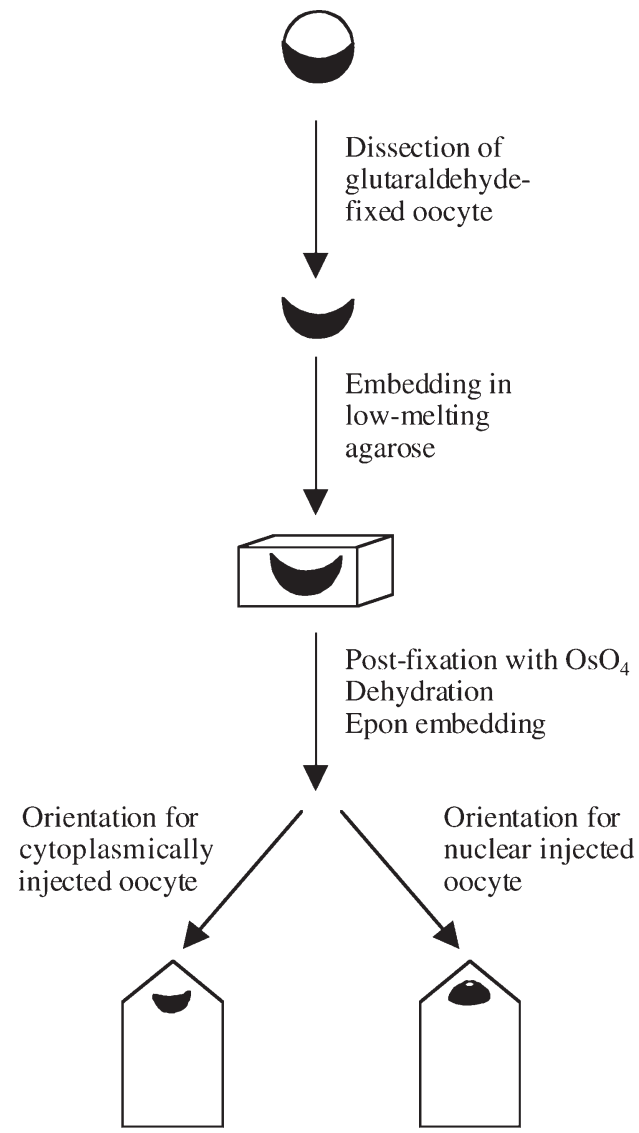

Fig. 4. Steps for preparing injected Xenopus oocytes for embedding in Epon. For detail, see Subheading 3.3.

9. Place samples on flat molds filled with fresh pure Epon. Orient the oocytes in such a way that the side of the nucleus closer to the injection site is trimmed and sectioned first (see Fig. 4). This is done with the help of a dissecting microscope.

10. Polymerize for $2 \mathrm{~d}$ at $60^{\circ} \mathrm{C}$.

11. Trim the specimen block so that sections can be made through the area of the oocyte that includes the nucleus.

12. With an ultramicrotome, obtain sections that are $50 \mathrm{~nm}$ thin. Transfer sections onto specimen EM grids. Stain grids with $2 \%$ uranyl acetate for $30 \mathrm{~min}$ and wash grids on 4 drops of distilled water. Stain with $2 \%$ lead citrate for $5 \mathrm{~min}$. Wash grids again on 4 drops of distilled water and let them dry. Examine grids using the EM.

\section{Notes}

1. The quality of colloidal gold depends on the cleanliness of the glassware and the freshness of the solution used. Even a minimal amount of contamination on the glassware or in the solutions used can interfere with the formation of the gold particles. 
2. Conjugation of proteins with colloidal gold depends on the charge of the protein. It is recommended to perform the reaction at a $\mathrm{pH}$ higher than the isoelectrical point of the protein to be conjugated. If this value is not known and the reaction does not work at neutral $\mathrm{pH}$, the $\mathrm{pH}$ of both the protein solution and the colloidal gold should be adjusted to 8.0 to 9.0 , and the flocculation test should be done again. Alternatively, the flocculation test can be performed at different $\mathrm{pH}$ levels.

3. BSA is used as a stabilizer. It adsorbs to bare areas on the surface of the gold particles and prevents the aggregation of the gold complexes.

4. Although the binding of proteins to colloidal gold is irreversible, freezing the gold-protein complexes is not recommended because the protein might dissociate at low temperatures. The gold-protein complexes can be stored for weeks at $4^{\circ} \mathrm{C}$. However, it is advised not to use old gold-protein complexes for transport assays.

5. Some batches of oocytes require longer collagenase treatments. It is advised to check whether after $1 \mathrm{~h}$ of collagenase treatment a glass needle (the needle used for microinjection) can be easily inserted into the oocyte. If this is not possible or if the oocytes still have follicles, they should be kept in the collagenase solution for an additional 15 to $30 \mathrm{~min}$.

6. Alternatively, instead of centrifugation, the microwell plate containing the oocytes (properly oriented, with the animal pole facing upward) can be left overnight at $4^{\circ} \mathrm{C}$. The next day, the nuclei should be visible in the animal pole.

7. Time-course experiments can also be performed by incubating different oocytes for different time lengths (i.e., 15, 30, 60, $120 \mathrm{~min}$, etc.) $(\mathbf{1 0}, 23)$. Experiments in which nuclear transport is inhibited through chilling are performed by precooling the oocytes at $4^{\circ} \mathrm{C}$ for at least $1 \mathrm{~h}$ before microinjection. The oocytes are then kept on an ice bath during microinjection, and after injection they are incubated at $4{ }^{\circ} \mathrm{C}$ for $1 \mathrm{~h}$. Inhibition experiments with WGA or antibodies are performed by first cytoplasmically injecting the inhibitor (10-20). After incubation for $2 \mathrm{~h}$ at room temperature, the gold-conjugated transport substrate is injected into the preinjected oocytes.

8. The purpose of this dissection is to eliminate most of the cytoplasm (so that a cross section through the nucleus of the Epon-embedded oocyte can easily be performed after the polymerization of Epon) and to help in the orientation of the sample during embedding (see Fig. 4). This dissection should be done before fixation in $\mathrm{OsO}_{4}$ because after this fixation the vegetal hemisphere becomes black, and it is indistinguishable from the animal hemisphere.

\section{Acknowledgments}

This work was supported by grants from the Canadian Institutes of Health Research (CIHR) and the Natural Sciences and Engineering Research Council of Canada (NSERC).

\section{References}

1. Newmeyer, D. D. and Wilson, K. L. (1991) Egg extracts for nuclear import and nuclear assembly reactions. Methods Cell Biol. 36, 607-634.

2. Adam, S. A., Sterne-Marr, R., and Gerace, L. (1990) Nuclear protein import in permeabilized mammalian cells requires soluble cytoplasmic factors. J. Cell Biol. 111, 807-816.

3. Dingwall, C., Sharnick, S. V., and Laskey, R. A. (1982) A polypeptide domain that specifies migration of nucleoplasmin into the nucleus. Cell 30, 449-458. 
4. Dabauvalle, M. C. and Franke, W. W. (1982) Karyophilic proteins: polypeptides synthesized in vitro accumulate in the nucleus on microinjection into the cytoplasm of amphibian oocytes. Proc. Natl. Acad. Sci. USA 79, 5302-5306.

5. Michaud, N. and Goldfarb, D. S. (1991) Multiple pathways in nuclear transport: the import of U2 snRNP occurs by a novel kinetic pathway. J. Cell Biol. 112, 215-223.

6. Jarmolowski, A., Boelens, W. C., Izaurralde, E., and Mattaj, I. W. (1994) Nuclear export of different classes of RNA is mediated by specific factors. J. Cell Biol. 124, 627-635.

7. Feldherr, C. M. (1969) A comparative study of nucleocytoplasmic interactions. J. Cell Biol. 42, 841-845.

8. Feldherr, C. M., Kallenbach, E., and Schultz, N. (1984) Movement of a karyophilic protein through the nuclear pores of oocytes. J. Cell Biol. 99, 2216-2222.

9. Richardson, W. D., Mills, A. D., Dilworth, S. M., Laskey, R. A., and Dingwall, C. (1988) Nuclear protein migration involves two steps: rapid binding at the nuclear envelope followed by slower translocation through nuclear pores. Cell 52, 655-664.

10. Panté, N. and Aebi, U. (1996) Sequential binding of import ligands to distinct nucleopore regions during their nuclear import. Science 273, 1729-1732.

11. Görlich, D., Panté, N., Kutay, U., Aebi, U., and Bischoff, F. R. (1996) Identification of different roles for RanGDP and RanGTP in nuclear protein import. EMBO J. 15, 55845594.

12. Finlay, D. R., Newmeyer, D. D., Price, T. M., and Forbes, D. J. (1987) Inhibition of in vitro nuclear transport by a lectin that binds to nuclear pores. J. Cell Biol. 104, 189-200.

13. Dabauvalle, M. C., Schulz, B., Scheer, U., and Peters, R. (1988) Inhibition of nuclear accumulation of karyophilic proteins in living cells by microinjection of the lectin wheat germ agglutinin. Exp. Cell Res. 174, 291-296.

14. Panté, N. and Kann, M. (2002) Nuclear pore complex is able to transport macromolecules with diameters of about $39 \mathrm{~nm}$. Mol. Biol. Cell. 13, 425-434.

15. Rabe, B., Vlachou, A., Panté, N., Helenius, A., and Kann, M. (2003) Nuclear import of hepatitis B virus capsids and release of the viral genome. Proc. Natl. Acad. Sci. USA 100, 9849-9854.

16. Fischer, U., Darzynkiewicz, E., Tahara, S. M., Dathan, N. A., Lührmann, R., and Mattaj, I. W. (1991) Diversity in the signals required for nuclear accumulation of U snRNPs and variety in the pathways of nuclear transport. J. Cell Biol. 113, 705-714.

17. Fischer, U., Sumpter, V., Sekine, M., Satoh, T., and Lührmann, R. (1993) Nucleo-cytoplasmic transport of U1 snRNPs: definition of a nuclear location signal in the SM core domain that binds a transport receptor independently of the $\mathrm{m}_{3} \mathrm{G}$-cap. EMBO J. 12, 573-583.

18. Michaud, N. and Goldfarb, D. S. (1992) Microinjected U snRNAs are imported to oocyte nuclei via the nuclear pore complex by three distinguishable targeting pathways. J. Cell Biol. 116, 851-861.

19. Huber, J., Cronshagen, U., Kadokura, M., et al. (1998) Snurportin1, an m3G-cap-specific nuclear import receptor with a novel domain structure. EMBO J. 17, 4114-4126.

20. Rollenhagen, C., Muhlhausser, P., Kutay, U., and Panté, N. (2003) Importin $\beta$-depending nuclear import pathways: role of the adapter proteins in the docking and releasing steps. Mol. Biol. Cell 14, 2104-2115.

21. Terns, M. P. and Goldfarb, D. S. (1998) Nuclear transport of RNAs in microinjected Xenopus oocytes. Methods Cell Biol. 53, 559-89.

22. Dworetzky, S. I. and Feldherr, C. M. (1988) Translocation of RNA-coated gold particles through the nuclear pores of oocytes. J. Cell Biol. 106, 575-584. 
23. Panté, N., Jarmolowski, A., Izaurralde, E., Sauder, U., Baschong, W., and Mattaj, I. W. (1997) Visualizing nuclear export of different classes of RNA by electron microscopy. RNA 3, 498-513.

24. Goldie, K. N., Panté, N., Engel, A., and Aebi. U. (1994) Exploring native nuclear pore complex structure and conformation by scanning force microscopy in physiological buffers. J. Vac. Sci. Technol. B 12, 1482-1485.

25. Allen, T. D., Rutherford, S. A., Bennion, G. R., et al. (1998) Three-dimensional surface structure analysis of the nucleus. Methods Cell Biol. 53, 125-138.

26. Akey, C. W. and Goldfarb, D. S. (1989) Protein import through the nuclear pore complex is a multistep process. J. Cell Biol. 109, 971-982.

27. Stewart, M., Whytock, S., and Mills, A. D. (1990) Association of gold-labelled nucleoplasmin with the centres of ring components of Xenopus oocyte nuclear pore complexes. J. Mol. Biol. 213, 575-582.

28. Slot, J. W. and Geuze, H. J. (1985) A new method of preparing gold probes for multiplelabeling cytochemistry. Eur. J. Cell Biol. 38, 87-93. 